\title{
Stage IIA Cervical Cancer AJCC v6
}

National Cancer Institute

\section{Source}

National Cancer Institute. Stage IIA Cervical Cancer A/CC v6. NCI Thesaurus. Code C6319.

Tumor without parametrial invasion. 